\title{
Percepções de jovens aprendizes sobre os processos de ensinar e de aprender ${ }^{1}$
}

\author{
Ana Maria Venâncio Gonçalves Imhoff \\ Camila Grimes \\ Edson Schroeder \\ Universidade Regional de Blumenau
}

\section{Resumo}

A presente investigação refere-se às percepções dos adolescentes do Programa Jovem Aprendiz (PJA) sobre aulas consideradas "chatas" e "legais", em uma escola profissionalizante, no Município de Florianópolis (SC). 0 objetivo foi conhecer e analisar as percepções dos jovens aprendizes sobre os processos de ensinar e aprender, e apresentar indicadores qualitativos que auxiliam na atividade docente. Na coleta de dados, utilizamos o grupo focal com dez adolescentes. Para os jovens, uma aula "chata" é focada na transmissão e recepção de conhecimento. E uma aula "legal” é aquela em que se utilizam estratégias de ensino com motivação e linguagem acessível.

Palavras-chave: Processos de ensinar. Processos de aprender. Recursos didáticos. Estratégia de ensino. Jovem Aprendiz.

1. Versão ampliada de trabalho apresentado no IX Seminário de Pesquisa em Educação da Região Sul (Anped Sul), 2012, sob o título “'Aula chata não!'- conhecendo as percepções dos adolescentes participantes do Programa Jovem Aprendiz sobre processos de ensinar e de aprender". 


\section{Young apprentices' perceptions about the processes of teaching and learning}

The present investigation refers to adolescents' perceptions of the Young Apprentice Program (YAP), on classes considered "boring" and "cool" in a vocational school, in Florianópolis (SC). The objective was to understand and analyze the perceptions of young apprentices on the processes of teaching and learning, and the present qualitative indicators which assist in teaching activities. In collecting data, we have used the focus group with ten adolescents. For the young apprentices the "boring" class is focused on the transmission and reception of knowledge. And a "cool" class is when it is used teaching strategies such as motivation and accessible language.

Keywords: Processes of teaching. Processes of learning. Teaching resources. Teaching strategy. Young Apprentice.

\section{Las percepciones de Jóvenes Aprendices sobre los procesos de enseñanza y aprendizaje}

La presente investigación se refiere a las percepciones de los adolescentes del Programa Joven Aprendiz (PJA), en las clases consideradas como "aburridas" y "estupendas" en una escuela de formación profesional, en Florianópolis (SC). El objetivo fue conocer y analizar las percepciones de jóvenes estudiantes en los procesos de enseñanza y aprendizaje, y presentar los indicadores cualitativos que ayudan en las actividades de enseñanza. En la recopilación de datos, se utilizó el grupo focal con diez adolescentes. Los jóvenes consideran la clase "aburrida" cuando esta se centra en la transmisión y recepción de conocimientos. Y las consideran "estupenda" cuando son usadas distintas estrategias de motivación y un lenguaje accesible.

Palabras clave: Procesos de enseñanza. Procesos de aprendizaje. Recursos para la enseñanza. Enseñanza de estrategia. Joven Aprendiz. 


\section{Introdução}

$\mathrm{Na}$ adolescência ocorrem, ao mesmo tempo, muitas transformações biológicas e psicológicas, o que faz dessa uma etapa muito importante para o ser humano. Nesse período, o adolescente vivencia a ansiedade da transição da infância para a fase adulta. Tanto os pais, com relação aos seus filhos, como os próprios adolescentes ainda não se sentem seguros para enfrentar os desafios da maturidade, mas já assumem seus diferentes estilos de vida e sinalizam suas escolhas e perspectivas de futuro. Nesse contexto, as questões de trabalho são discutidas no seio familiar e os jovens começam a se preocupar com o seu futuro profissional. 0 Programa Jovem Aprendiz (PJA) ${ }^{2}$ figura como possibilidade de trabalho e renda na adolescência, uma vez que atende às exigências da legislação trabalhista vigente no Brasil.

O PJA é um programa do governo federal, de abrangência nacional, em parceria com instituições credenciadas ao governo que oferecem cursos profissionalizantes para jovens com idade entre 14 e 24 anos, voltados à preparação para o exercício de funções no comércio e na indústria. Para o comércio são oferecidos, entre outros, os cursos de Aprendizagem em Vendas, Aprendizagem em Supermercados, Aprendizagem em Hotelaria e Aprendizagem em Atividades Operacionais de Empresas de Asseio e Conservação.

Os adolescentes ${ }^{3}$ são recrutados e selecionados pelas empresas dos segmentos dos cursos ofertados, e matriculados nas escolas credenciadas ao PJA. Qualquer jovem com a idade permitida pode iniciar suas atividades profissionais por intermédio do PJA, contando com a legislação para formalizar sua função. Os jovens selecionados são, em sua grande maioria, pertencentes às classes populares e necessitam trabalhar para auxiliar os pais na complementação da renda familiar. Muitos desses pais, mormente aqueles que não tiveram a oportunidade de estudar, visualizam no projeto a chance de os filhos trabalharem sem a necessidade de estes abandonarem os estudos.

O PJA pode ser compreendido como uma tríade - empresa/curso/escola -, porque, ao ingressarem, os jovens devem obrigatoriamente trabalhar na empresa

2. Utilizamos a expressão "jovem aprendiz" seguindo a orientação do Ministério do Trabalho e Emprego (MTE), orientação apresentada em reuniões com representantes do órgão e do empresariado. 0 intuito dessa orientação é substituir o termo consensual "menor aprendiz" (da época em que a legislação previa idade entre 14 e 18 anos), pois a atual legislação define o aprendiz com idades entre 14 e 24 anos, e utiliza somente o termo "aprendiz". Além disso, a instituição estudada, que oferece cursos em todo o território nacional, denomina o programa de aprendizagem como Programa Jovem Aprendiz (PJA).

3. Utilizamos os termos "adolescentes" e "jovens" como sinônimos porque a escola profissionalizante pesquisada procura contemplar os estudantes com idades de 14 a 19 anos, fase compreendida como adolescência e também juventude. Ressaltamos, ainda, que os sujeitos estudados encontram-se na faixa etária de 14 a 17 anos, por isso utilizamos aqueles dois termos. 
que os contratou, realizar o curso de aprendizagem em uma instituição parceira do programa com o governo federal e frequentar o ensino médio regular, caso ainda estejam na idade de conclusão. Os jovens, então, passam a cumprir uma expressiva carga de atividades diárias, o que, para a maioria dos participantes, constitui-se num ritmo distante das obrigações até então exigidas. Essa sobrecarga de obrigações ocasiona, muitas vezes, falta de ânimo para o aprendizado, fato agravado, algumas vezes, pelo reduzido dinamismo por parte do professor nas aulas oferecidas no curso. Os jovens exercem as funções de aprendizagem prática nos seus postos de trabalho, intercalando-as com suas atividades na escola e no curso, para cumprir a obrigatoriedade da lei. 0 que pode parecer algo normal para os adultos, parece, aos olhos dos adolescentes, uma grande carga de atividades, com reflexos sobre a atenção e a dedicação aos estudos. Eles alegam que as aulas são cansativas e muito semelhantes às que são aplicadas na escola.

Nosso objetivo central foi conhecer e analisar as percepções dos jovens aprendizes do curso de vendas, em uma escola de ensino profissionalizante no Município de Florianópolis (SC), sobre os processos de ensinar e aprender. Outro objetivo, além desse, foi apresentar indicadores qualitativos que auxiliam na atividade docente, com o intuito de aprimorar reflexões sobre o fazer pedagógico da equipe de docentes e gestores participantes do PJA.

$\mathrm{Na}$ investigação, de abordagem qualitativa, a coleta de dados foi realizada por meio de um grupo focal com dez adolescentes que frequentam o curso de vendas. Definimos como tópico guia da discussão uma aula considerada "chata" pelos jovens aprendizes. As análises, a partir dos resultados, foram feitas com base nas contribuições teóricas de Coll (1994, 2004), Tosi (2001), Pozo (2002), Delizoicov, Angotti e Pernambuco (2002), Vasconcellos (2005) e Pozo e Crespo (2009).

\section{O Programa Jovem Aprendiz}

0 aprendiz, segundo a Lei no 10.097 , de 19 de dezembro de 2000, é todo indivíduo com idade entre 14 e 24 anos incompletos e com vínculo empregatício especial, por meio de contrato de aprendizagem com uma empresa, para a realização de curso de profissionalização em uma das instituições autorizadas pela Lei (Śenac/ SC, 2009).

De acordo com a legislação trabalhista brasileira, uma pessoa só pode iniciar suas atividades em um trabalho, de maneira formal, após os 16 anos, exceto na condição de aprendiz, a partir dos 14 anos, desde que esteja estudando e inserido em um programa que a coloque em situação e ambiente de aprendizagem (Senac) SC, 2009).

A instituição pesquisada, assim como outras que tenham parceria com 0 governo federal/Ministério do Trabalho e Emprego, disponibiliza cursos voltados 
para o comércio para os adolescentes que queiram, na condição de aprendizes, iniciar suas primeiras experiências profissionais. Nesse contexto, de acordo com a Lei $n^{0} 11.180 / 2005$, os adolescentes iniciam suas atividades nas empresas que necessitam preencher suas cotas de jovens aprendizes lempresas de médio porte que devem, obrigatoriamente, compor de $5 \%$ a $14 \%$ do seu quadro funcional com jovens aprendizes), e no curso focado para as suas atribuições na empresa que os contratou. Os jovens, ao serem contratados pelas empresas parceiras do programa, são direcionados às instituições que oferecem cursos no segmento da empresa contratante (Senac/SC, 2009).

Quando o adolescente é selecionado e contratado como aprendiz, necessita cumprir uma carga horária semanal de vinte horas. Destas, oito horas semanais são dedicadas ao desenvolvimento das atividades como estudante na instituição que o capacita (educação profissional); nas doze horas semanais restantes, ele exerce suas funções de aprendiz nas empresas contratantes. Além disso, o adolescente está matriculado na escola de educação formal. Na instituição de educação profissional, ele cumpre quatro horas em dois dias da semana, estudando conteúdos específicos do seu curso - no nosso caso, Aprendizagem em Vendas: Eixo Tecnológico em Gestão e Negócios - e totalizando uma carga horária de 880 horas, distribuídas em 400 horas na instituição (educação profissional) e 480 horas no ambiente de trabalho (empresa contratante).

0 aprendiz em vendas atua como auxiliar em vendas e desenvolve atividades relacionadas ao atendimento ao cliente em organizações do comércio, turismo e prestadoras de serviço de médio e grande porte, de direito público ou privado. Para o desenvolvimento das competências necessárias à formação de um aprendiz em vendas, o plano de curso está organizado em unidades curriculares, como Promoção do Trabalho em Equipe; Princípios de Economia Pessoal; Educação para o Autocuidado em Saúde; Cidadania, Direitos e Deveres; Rotina de Reposição de Produtos; Princípios dos Processos de Vendas; etc.

Ao planejar uma aula, o professor orienta-se por um plano de curso estruturado pelo programa, e as ações educacionais são orientadas em função de um currículo já existente. A partir daí, o professor planeja seu processo de ensino, levando em consideração os recursos e as estratégias mais adequadas aos objetivos e necessidades dos estudantes.

\section{Conhecendo os procedimentos metodológicos e os sujeitos da investigação}

Consideramos este estudo como uma abordagem qualitativa, pois, de acordo com Bauer e Gaskell (2002, p. 68), não se trata somente de "[...] contar opiniões ou pessoas, mas, ao contrário, explorar o espectro de opiniões, as diferentes 
representações sobre o assunto em questão". Nesse sentido, optamos por coletar os dados fazendo uso do grupo focal, uma vez que isso possibilita um debate aberto e acessível, tratando-se de assuntos de interesse comum. Para Bauer e Gaskell (2002, p. 79), o debate permite "uma troca de pontos de vista, ideias e experiências, embora expressas emocionalmente e sem lógica, mas sem privilegiar indivíduos particulares ou posições". Em nosso caso, constituímos um grupo com dez participantes escolhidos de forma aleatória, por meio de um sorteio efetivado em uma turma com 34 estudantes do curso de vendas do PJA. Para o sorteio foram considerados os estudantes que tinham, nas unidades curriculares, frequência maior ou igual a $75 \%$.

0 grupo focal foi realizado em um espaço confortável, devidamente organizado. As manifestações foram gravadas em áudio, para posterior transcrição, com a autorização de todos os participantes. Utilizamos como tópico guia para promover a discussão este questionamento: "o que é uma aula 'chata' para você?"

Empregamos como unidade de análise as percepções dos estudantes sobre aulas consideradas "chatas" e "legais". Desta unidade originaram-se as categorias de análise, que foram definidas pela metodologia de análise do conteúdo (Vergara, 2008), a qual propõe a construção de categorizações com base na análise das percepções, após o período de coleta de dados.

A partir dos dizeres dos adolescentes, identificamos as seguintes categorias de análise: (a) aula focada na transmissão e recepção de conhecimento e (b) aula com utilização de estratégias de ensino diversificadas.

\section{As percepções dos estudantes sobre aulas consideradas "chatas" e “legais"}

Apresentamos, neste momento, as análises das categorias apontadas neste estudo.

\section{a) Aula focada na transmissão e recepção do conhecimento}

Os adolescentes identificaram como aula "chata" aquela em que o professor utiliza a lógica da transmissão e recepção de conhecimento, conforme exposto no excerto: “[...] pra mim, aula chata é aquela que o professor só fala” (Adolescente 7). Apesar do conhecimento já acumulado sobre os processos de ensinar e aprender, bem como das mudanças no ensino escolar, a lógica transmissão-recepção ainda é bastante utilizada. Contudo, em sala de aula, o professor tem a importante função de atuar como mediador dos processos de construção do conhecimento, visto que as exposições dogmatizadas prejudicam a aprendizagem. Nesse sentido, Tosi (2001, p. 162) infere que "o que é objeto de crítica nos dias atuais é a priorização da exposição dogmatizada [...] a aprendizagem se dá estando o aluno em atividade. 
Somente escutar não surte o efeito desejado de verdadeira aprendizagem".

Corroborando essa reflexão, Pozo e Crespo (2009, p. 22) inferem que "não é mais possível conceber a aprendizagem como uma atividade apenas de reprodução ou cumulativa". Em sala de aula, o desenvolvimento do indivíduo, bem como o reconhecimento de sua identidade, é fundamental para que ocorra a aprendizagem. Ao encontro desse pensamento, evidenciamos as reflexões de Coll (1994, p. 93):

$\mathrm{Na}$ interação social, a criança aprende a regular os seus processos cognitivos, seguindo as indicações e diretrizes dos adultos, produzindo-se um processo de interiorização mediante o qual o que pode fazer ou conhecer a princípio com a ajuda deles (regulamentação interpsicológica) transforma-se progressivamente em algo que pode fazer ou conhecer por si mesmo (regulamentação intrapsicológica).

Nesse sentido, Delizoicov, Angotti e Pernambuco (2002) destacam que o estudante é sujeito de sua aprendizagem; ele é que realiza a ação, construída entre a interação do sujeito com meio natural e social. Enfatizam, ainda, que cabe ao professor mediar e criar situações para facilitar o aprendizado. Complementado esse pensamento, os jovens aprendizes indicam, ainda, como elemento de uma aula "chata", a falta de diálogo e interação entre professor/estudante e estudante/ estudante, bem como a ausência de dinâmicas que promovam as interações, de acordo com os excertos: "para mim, é uma aula que não tem diálogo, que ah... só fica escrevendo" (Adolescente 1). "Com certeza, aula mais chata é a que os alunos não participam... que só o professor fala... com certeza!" (Adolescente 5). Ou ainda:

Eu já não acho que é questão de assunto, que é a questão de ser descontraída a aula e o professor dar abertura pra gente falar, querendo ou não você vai falando, falando, falando, e tem que ter aquela dinâmica assim com a turma, [...] o professor acaba tipo falando uma curiosidade, e aí os alunos pergunta. (Adolescente 3)

As interações e os diálogos decorrentes são fundamentais em sala de aula, uma vez que podem propiciar um ambiente motivador, que é essencial para o processo de construção de significados. As relações sociais, no contexto educativo, possibilitam as trocas de conhecimentos vivenciados pelos estudantes com os conhecimentos aprendidos no ambiente escolar, resultando, assim, no desenvolvimento cognitivo dos adolescentes. Ao encontro desse pensamento, Delizoicov, Angotti e Pernambuco (2002) enfatizam que os estudantes se constituem como sujeitos coletivos, pois interagem e estabelecem relações com o meio físico e social, no processo de construção de conhecimentos. Os autores destacam, também, que no processo de ensino e de aprendizagem é fundamental a interação dialógica, que possibilita que as interpretações sejam problematizadas. A utilização do diálogo em sala de aula pode transformar-se em um avanço com relação à exposição 
dogmática (Tosi, 2001), uma vez que esta inviabiliza qualquer interferência por parte dos estudantes, em relação ao seu professor e aos conhecimentos ensinados. A exposição dialogada pode aprimorar o nível de elaboração de conhecimento, porque permite uma efetiva interação entre os envolvidos. 0 fundamento dessa prática é o da participação mais ativa por parte de estudantes e professor, e contrapõe-se à figura deste como mero transmissor. Para Vasconcellos (2005, p. 86),

Esta postura de construção do conhecimento implica uma mudança de paradigma pedagógico, qual seja, ao invés de dar o raciocínio pronto, de fazer para/pelo aluno, o professor passa a ser o mediador da relação educando-objeto de conhecimentorealidade, ajudando-o a construir a reflexão, pela organização de atividades, pela interação e problematização; os conceitos não devem ser dados prontos; podem ser construídos pelos alunos, propiciando que caminhem para a autonomia.

0 professor não pode ser indiferente nos processos de ensinar e aprender, pois sua ação não é autocentrada, meramente expositiva; ao contrário, sua ação deveria levar em conta as vivências anteriores do estudante. Nesse sentido, compete ao professor a função de preparar um ambiente instrutivo de forma que os estudantes aprendam partindo das suas próprias atividades, de modo que eles não recebam passivamente as informações. Dessa maneira, confere-se ao professor e ao processo por ele gerado uma função social de extrema relevância, definindo o ensino como um procedimento de influências e interferências planejadas, direcionadas e conscientes sobre os métodos naturais de desenvolvimento do jovem aprendiz. Em sala de aula, o estudante deveria aprender a transformar uma capacidade "em si" numa capacidade "para si". A vida consiste num trabalho criativo, e, ao transformá-la nesse processo criativo, o indivíduo atingiria novos níveis de insight e de compreensão.

A interação e o dinamismo são qualidades de uma boa aula presentes no discurso dos adolescentes em vários momentos: conforme exposto nestes excertos: "primeiro, não tendo sempre a mesma coisa todo dia, passar no quadro explicar... passar no quadro explicar... passar no quadro explicar... Alguma coisa pra ti interagir... descontrair, sei lá.. alguma coisa tipo... vai saí... pelo menos... trocar de sala" (Adolescente 4). Ou ainda: "é aquilo perguntar, debater, e aí todo mundo começa a conversar [...] como uma forma de dinâmica, né... quando os professores colocam mais [...] a aula fica bem legal". (Adolescente 5)

Os processos interativos e dinâmicos são indispensáveis à aprendizagem, pois, quando o professor propõe situações-problema aos estudantes, curiosidade destes pode ser despertada, e as relações sociais e discussões são potencializadas, o que facilita o processo de aprendizagem. De acordo com Coll (1994), o ser humano interage com o meio desde o seu nascimento, e essa interação é mediada pela cultura, sendo os pais, os educadores e todos os outros sujeitos que circundam 
o indivíduo os principais agentes mediadores. Assim, as relações interpessoais estabelecidas proporcionam o desenvolvimento da aptidão cognitiva. A esse respeito, Coll (1994, p. 131) infere que "a atividade cognitiva do aluno que está na base do processo de construção e modificação de esquemas inscreve-se, de fato, no domínio de uma interação ou interatividade, em primeira instância professoraluno, mas também aluno-aluno".

Os jovens aprendizes valorizaram a importância das aulas dinâmicas e da motivação docente, conforme estes excertos: "se os professores trouxessem mais dinâmicas, talvez a aula fosse mais legal" (Adolescente 10).

Acho que tem que ter dinâmica, né, se não tiver dinâmica a aula não rende, e as pessoas ficam com sono [...], eu acho dinâmica [...] essencial para uma aula, e a vontade do professor de tá explicando aquilo. Se ele tá fazendo alguma coisa por obrigação e não por gostar, ele acaba transmitindo isso pro aluno, e o aluno também não vai tá interessado no que ele passou. (Adolescente 2)

A realização de atividades dinâmicas e motivadoras em sala de aula pode promover o desafio, que, por sua vez, pode instigar o estudante na busca de soluções. Coll (1994, p. 100) realiza importante reflexão sobre a capacidade humana e os estímulos: "a ideia de um ser humano relativamente fácil de moldar e dirigir a partir do exterior foi progressivamente substituída pela ideia de um ser humano que seleciona, assimila, processa, interpreta e confere significações aos estímulos e configurações de estímulos".

A motivação interfere diretamente nos processos de ensino. Conforme as reflexões de Pozo (2002), aprender significa mudança; para tanto, a motivação torna-se condição essencial nesse processo. A aula descontraída e dinâmica, isto é, que motiva a aprender, foi avaliada positivamente pelos adolescentes, conforme exposto no excerto abaixo:

[...] ninguém entende, tem dificuldade... se ele fica só passando, explicando, é horrível... então uma forma que seria muito bom de fazer uma aula bem assim... descontraída, era ele fazer uma brincadeira... alguma... é a dinâmica na realidade, é a própria dinâmica em si que torna... mais descontraída. (Adolescente 5)

Adolescentes são motivados por desafios e aprovam tarefas que caracterizam competição, conforme exposto nestes excertos: "todo mundo quer ganhar, quer ser melhor que o outro, e todo mundo que acabar [...]" (Adolescente 9). E complementa-se: "e participa daí" (Adolescente 5). Pozo e Crespo (2009, p. 40) inferem que "sem motivação não há aprendizagem escolar". Complementando esse pensamento, Coll (1994) enfatiza que, para a realização da aprendizagem, faz-se necessária a utilização de incentivos motivacionais, para favorecer um desequilíbrio entre os conhecimentos prévios do estudante e os conhecimentos 
legitimados cientificamente, gerando, desse modo, motivação para a superação do desafio imposto. Pozo (2002) infere que as tarefas de aprendizagem necessitam ser planejadas de maneira que os estudantes se defrontem com situações-problema abertas, de preferência em grupo, ao contrário de exercícios repetitivos. Assim, de forma progressiva, eles podem tomar decisões e definir estratégias para a resolução da tarefa.

A motivação e a dedicação docente também foram indicadas pelos adolescentes como elementos de uma aula "legal", de acordo com excerto abaixo:

Tem professor que se dedica a... dar aula, [...] tem professor que ama fazer aquilo, né... tenho um professor que ele pega a matéria [...] e faz o que gosta, né, mas ele ficava uma semana inteira até as duas da manhã assim... mais ou menos preparando a aula... pra explicar tudo bem certinho... pesquisando na internet... eu acho que isso também faz uma aula ficar boa. (Adolescente 10)

A ausência de motivação pode ser uma das causas da fragilidade na aprendizagem escolar, por isso é de grande importância o conhecimento das condições que favorecem o processo de motivação de estudantes e professores. Nesse sentido, Pozo (2002, p. 145) discute que

A possibilidade que um professor tem de mover seus alunos para a aprendizagem depende em grande parte de como ele mesmo enfrenta a sua tarefa de ensinar le aprender ensinando). A motivação dos alunos não pode se desligar muito da que têm seus professores, principalmente naqueles contextos que constituem uma verdadeira comunidade de aprendizagem, em que os alunos e professores compartilham juntos muito tempo de aprendizagem.

Para finalizar, foi identificada também como aula "legal" a que desperta a atenção dos adolescentes, de acordo com este excerto:

Eu acho que, tipo, trazer uma aula assim, com bastante emoção assim... e trazer aquele assunto pros alunos querer aprender [...] pra eles ficar atento, assim, pra descobrir que tirar as dúvidas deles, entendeu? Querer saber do assunto mesmo, querer conhecer sobre aquilo. (Adolescente 9)

Despertar a atenção dos adolescentes é um dos componentes principais no processo de ensino. Conforme Pozo (2002), para realizar uma aprendizagem eficaz, faz-se necessária a ativação dos processos de atenção, e sua manutenção depende do sucesso da atividade de aprendizagem. 0 autor complementa:

a diversificação das tarefas e situações de aprendizagem não só vai favorecer a manutenção da atenção dos alunos como também é uma das condições mais eficazes para ativar outros processos auxiliares de aprendizagem, como a recuperação e transferência do aprendido. (Pozo, 2002, p. 151) 
Nessa categoria, os adolescentes apresentaram importantes indicadores, com implicações para a atividade docente, que podem contribuir para os processos de ensino e de aprendizagem. Eles apontaram que as questões comportamentais relacionadas ao professor, tais como motivação, capacidade de motivar e capacidade de proporcionar interações discursivas, que gerem maior diálogo e dinamicidade em sala de aula, poderiam evitar a realização de aulas focadas somente na transmissão e recepção de informações.

\section{b) Aula com utilização de estratégias de ensino diversificadas}

Os adolescentes trouxeram exemplos das experiências de aprendizagem compreendidas por eles como "legais". Na unidade curricular Educação para o Autocuidado em Saúde, em uma aula sobre a temática Educação Sexual, eles enfatizaram em suas argumentações a importância da diversidade de recursos, conforme exposto nestes excertos: "ela trouxe uma banana... (risos)... uma camisinha..." (Adolescente 6). Ou, ainda: "os outros professores não fazem isso, né? Ah, é assim que se coloca uma camisinha, e pronto. Ela deu uma banana pra cada um, colocou ali, e agora, como faz, muita gente ali não sabia colocar uma camisinha" (Adolescente 1). Em sala de aula, a diversidade de estratégias pode facilitar a aprendizagem, pois estimula a curiosidade dos jovens. Pozo (2002) sugere o ensino dos conteúdos por meio de diversos cenários e tarefas, ou seja, a utilização de recursos didáticos distintos associados aos desafios das atividades subsequentes. Os estudantes ressaltaram o grande valor das situações contextualizadas, isto é, a consideração dos conhecimentos cotidianos como um interessante ponto de partida para aprofundar os conhecimentos, como demonstrado neste excerto:

Tipo assim, antes de começar a aula ela ainda perguntou, assim, como conhecia o nome da vagina e do pênis, pra todo mundo se soltar, entendeu? Pra todo mundo, assim, tá, não ficar com vergonha, pra depois ela começar a aula, assim, pra todo mundo poder participar junto, não ficar com vergonha. (Adolescente 1)

Nesse sentido, Delizoicov, Angotti e Pernambuco (2002) ressaltam a importância da situação contexto, em que o professor introduz seus estudantes no universo conceitual, por meio de suas vivências. As situações contexto, em sala de aula, permitem ao professor realizar uma aproximação entre os conhecimentos espontâneos experienciados pelos estudantes e os conhecimentos científicos ensinados no ambiente escolar. Desse modo, a situação contexto pode ser uma importante estratégia de ensino.

Os adolescentes mencionaram o vídeo como um interessante recurso didático, conforme exposto nestes excertos: "eu acho que quando o professor é legal... e faz a aula legal... o filme também fica interessante... acho que todo aluno gosta 
de quando é filme [...], acho que a galera gosta bastante de vídeo" (Adolescente 10). Referente ao vídeo, ainda, os adolescentes sinalizaram a preferência por documentários associados aos debates, devido à dinamicidade e à possibilidade de aprofundamento de diferentes perspectivas, conforme este excerto: "eu acho, assim, que um vídeo com debates, várias pessoas, é mais interessante, porque às vezes só uma pessoa falando é só aquilo, não vai ter como uma discordância" (Adolescente 5). Quanto aos filmes, os adolescentes mostraram-se conscientes do potencial que apresentam para a aprendizagem:

Eu acho que, quando tem uma moral, [...] o filme do Jamaica Abaixo de Zero, né? Ele tem uma moral legal, né? Teve força de união, força de vontade. Daí, sim. Mas, tipo, trazer um filme só por ver, aí acho, sei lá, que às vezes é uma dinâmica um pouco estranha. (Adolescente 10)

Ou, ainda:

[...] o professor, antes de passar o filme, ele já apresenta a proposta, quando a professora foi passar [...] já mandou a gente analisar certos pontos, pra gente já focar bem naquilo, [...] é um fator que torna o vídeo sempre produtivo, pra gente aproveitar o conteúdo do vídeo. (Adolescente 5)

Os filmes, documentários e suas temáticas podem contribuir para o processo de aprendizagem e desenvolvimento dos adolescentes. Nesse sentido, Coutinho (2009, p. 5) ressalta que

Ao colocar imagens e sons em movimento, o cinema, e cada filme em particular, faz aflorar as emoções, percebidas por meio dos sentidos, todos os sentidos, embora tocados pela visão e pela audição. 0 cinema propõe outras formas de percepção e, portanto, de construção de subjetividades. Cada um constrói a sua própria percepção e pode expressá-la em ambientes que favoreçam a troca de pontos de vista. Ao conhecer o ponto de vista do outro, o meu será, com certeza, enriquecido.

Outra estratégia mencionada pelos adolescentes foi a dramatização:

0 meu professor [...] ele explica muito bem assim... porque ele... explica assim meio que meio fazendo que um teatro, ele... é novo, ele fala como a nossa linguagem... e faz meio que teatro... falando com gestos, assim, e falando assim, todo mundo ficava prestando atenção, assim... todo mundo entendeu, todo mundo entende só pela explicação que ele deu ali. (Adolescente 9)

A dramatização oferece muitas possibilidades de ensino, sobretudo quando consiste na encenação do cotidiano em que os estudantes estão inseridos. 0 professor tem um importante papel em realizar as aulas com criatividade, 
fazendo uso de diversos recursos, em constante movimento. Para Pozo (2002), a aprendizagem eficaz necessita de um professor mediador, que assume diferentes funções e realiza tarefas, desfazendo a monotonia didática, a qual compromete 0 desejo de aprender, bem como o desejo de ensinar.

A saída a campo, ou viagem de estudo, foi outra estratégia extraclasse identificada como elemento de uma aula "legal" pelos adolescentes, segundo este dizer: "Fazer uma aula fora da sala... saída de campo" (Adolescente 7). De acordo com Martín e Mauri (2004), todas as atividades escolares, formais ou informais, representam grande valor educacional. As atividades extraescolares, como as viagens de estudo, podem desenvolver capacidades relevantes à aprendizagem, muitas vezes difíceis de trabalhar em sala de aula, tais como a capacidade motora, a afetiva e a de inserção e atuação social.

A linguagem e/ou fala acessível foi elencada pelos adolescentes como uma estratégia de uma aula considerada "legal", conforme o excerto apresentado abaixo:

[...] na hora que o professor utiliza as palavras que a gente usa no dia a dia, ah... meu Deus, é muito melhor, a gente consegue entender... 100\%... Eu tenho uma professora [...] só que ela fala de um jeito... a aula dela não é chata, só que a maneira que ela coloca as palavras se torna tão difícil que a gente fica... não consegue entender [...]. (Adolescente 5)

Segundo Schmitz, (1993, p. 146), o professor tem como função "apresentar os recursos de forma clara, simples e acessível ao aluno, visando fundamentalmente a dar condições de desenvolvimento da capacidade de compreensão, interpretação e aplicação, evitando símbolos confusos e deformações artificiais".

De acordo com Coll (2004), quando professor e estudante entram em contato com um novo conteúdo de aprendizagem, normalmente possuem representações diferentes sobre o referido conteúdo. Nesse momento, a tarefa é estabelecer um sistema inicial com um mínimo de significados compartilhados. Posteriormente, uma vez estabelecida a conexão, a tarefa consiste em ampliar e enriquecer o compartilhamento de representações entre estudante e professor próximo dos significados culturalmente aceitos desses conteúdos.

Para os jovens aprendizes, uma boa aula é aquela em que o professor diversifica as estratégias de ensino e escolhe recursos didáticos criativos, proporcionando aulas mais interessantes e motivadoras, em se tratando principalmente de adolescentes. Nessa fase, os jovens ficam inquietos, e a consolidação da personalidade e a busca pela identidade pessoal os fazem mais questionadores e ávidos por manifestarem suas opiniões e desejos (Palacios; Oliva, 2004). Além das mudanças físicas e as profundas transformações psicológicas que os jovens enfrentam nessa fase, vale lembrar que eles estão familiarizados com a tecnologia, que avança a passos largos. 
Atualmente, as propostas didáticas ressaltam a importância da construção de um processo de parceria em sala de aula, deslocando o foco da ação docente e do ensino para a aprendizagem e destinando ao aluno o espaço do aprendiz. Menos maduro que o professor, o aluno necessita da condução deste no processo, mas precisa participar dele ativamente; a aprendizagem é uma ação intencional, direcionada e deliberada por parte do aluno, exigindo esforços conjuntos com o professor para o domínio do conhecimento. (Anastasiou; Alves, 2004, p. 57-58)

É nesse contexto que o professor tem o desafio e a necessidade de repensar suas práticas educativas. Os recursos didáticos e as estratégias de ensino, aliados a diversos outros fatores que podem possibilitar a eficácia dos processos de ensinar e de aprender, são de grande importância em sala de aula. Vasconcellos (2005) infere que, em ambientes de ensino, estratégias como a problematização, a exposição dialogada, o trabalho de grupo, pesquisa, seminário, experimentação, debate, jogos educativos, dramatização, produção coletiva, filmes e o estudo do meio, entre outros, são princípios metodológicos que poderão auxiliar, de forma significativa, o processo de construção do conhecimento pelos jovens aprendizes.

De acordo com Vasconcellos (2005), a definição da estratégia de ensino e a escolha dos recursos didáticos, que resultam em aulas mais dinâmicas e estimulantes, devem ser aliadas à análise de situações contexto; ou seja, na construção do conhecimento em sala de aula, o professor necessita obter informações a respeito do que pensam e como pensam os estudantes. Parte-se do princípio de que o novo vai ser construído a partir do existente. "O professor parte do que o aluno tem de quadro de significação e vai introduzindo, pela problematização, novos elementos para a análise" (Vasconcellos, 2005, p. 89). A aprendizagem e o desenvolvimento intelectual são processos em que os jovens aprendizes se apropriam dos conhecimentos e, simultaneamente, constituem-se nesse processo. Não se trata de uma apropriação passiva, mas sim de uma transformação dos conhecimentos e do próprio sujeito no qual esse processo se constitui. As ações do professor visam provocar o pensamento do estudante e situações que despertem o interesse pelo aprendizado, bem como acompanhar e incentivar a elaboração de respostas aos problemas levantados.

As considerações no sentido de que o professor deve rever e aprimorar suas práticas são muito discutidas, mas quais são as verdadeiras estratégias apontadas pelos adolescentes como estimulantes? 0 professor encontra o desafio de estar entre jovens cercados pelas informações, mas com dificuldade de controlar as emoções e incertezas sobre o que esse processo demanda. Esse desafio se amplia frente à realidade dos adolescentes de hoje, uma vez que eles fazem parte de uma geração com profundas conexões com as tecnologias midiáticas. Computadores, celulares com funções diversas e o acesso fácil e quase ilimitado às informações, definitivamente não são mais novidades para essa geração.

Contudo, ressaltamos que não existem metodologias de aprendizagem 
perfeitas, pois os processos de ensinar e aprender possuem grande complexidade e envolvem diferentes fatores. De acordo com Pozo (2002, p. 249),

[...] a aprendizagem é um problema complexo, um sistema de interações, a que não se adéquam bem as categorias morais de bem e de mal, de forma que não podem se identificar 'boas' e 'más' práticas didáticas, mas sim condições eficazes ou não para se alcançar os fins estabelecidos.

Para Coll e Solé (2004), a confluência e a interconexão de vários fatores, tais como a atividade educacional e de ensino do professor, a atividade de aprendizagem dos estudantes, a interação entre professor e estudante, bem como entre estudante e estudante, conteúdos de aprendizagem, atividade conjunta de estudantes e docente, e atividades discursivas, entre outros, constituem a essência dos processos de ensinar e aprender, a qual precisamos compreender e aperfeiçoar.

Por meio desta pesquisa, constatamos que os jovens aprendizes possuem discursos distintos e vivências positivas e negativas relacionadas às suas percepções já construídas sobre o ensino e a aprendizagem. Cabe aos professores trabalhar para que essas experiências tornem-se cada vez mais positivas; e ao sistema educacional como um todo, apoiar as necessidades de professores e estudantes com vistas à aprendizagem.

\section{Considerações finais}

Os jovens aprendizes do PJA pontuaram que uma aula "chata" - portanto, nada estimulante - acontece quando está focada somente na transmissão e recepção de conhecimento; quando a aula é desprovida de diálogo e interação professor/ estudante, estudante/professor e/ou estudante/estudante; quando a aula é desprovida de dinamismo e motivação; e quando os conteúdos já são conhecidos dos adolescentes.

Os adolescentes nos revelam, ainda, que a aula pode ser estimulante e "legal" quando o professor apresenta diversas estratégias; quando a aula tem interação e dinamismo, despertando a atenção dos estudantes; quando a aula tem professores motivados e motiva os estudantes; e quando a aula tem uma linguagem acessível.

Colocamos em evidência as estratégias de aula apontadas como estimulantes ao aprendizado pelos sujeitos pesquisados: aulas em que os professores levam recursos didáticos que facilitam a internalização e transferência do conhecimento, como, por exemplo, jogos e/ou objetos que são alvo de discussão em sala de aula e permitem a visualização e o toque. Eles enfatizam o valor das situações contexto, ou seja, o levantamento de conhecimentos cotidianos do estudante, pois 
este desenvolve afetividade com o conhecimento científico e, assim, possui maior facilidade de internalizá-lo. Apontam, ainda, a utilização de filmes e vídeos em sala de aula como algo positivo e estimulante. Por fim, indicam a dramatização como possibilidade de ensino.

Com base na análise dos dados apresentados para este estudo, é possível inferir alguns indicadores a partir das percepções que os estudantes adolescentes do PJA têm construído sobre a aula "chata" e a aula "legal". A maneira como o professor pensa e conduz a sua aula é fundamental para o aprendizado do estudante. Nesse sentido, apresentamos os seguintes indicadores:

a. A função mediadora dos recursos de ensino tem consequências sobre as aprendizagens dos estudantes. A mente é desenvolvida quando interage com os materiais disponíveis pela cultura, no entanto as interações não são determinadas pelos recursos em si, mas pelos objetivos e metas de trabalho, definidos e determinados socialmente. Portanto, os professores não deveriam perceber os recursos apenas como facilitadores da aprendizagem, mas também como promotores de desenvolvimento.

b. Materiais escritos também são recursos que devem estar presentes nas aulas do PJA. Sua utilização pode prover os meios para a reflexão, bem como o emprego da sistematização, uma vez que introduzem e auxiliam os estudantes na compreensão das diferentes formas de representação utilizadas pela comunidade: os conceitos visuais e verbais.

c. Nas interações discursivas, as discussões são momentos particularmente interessantes, uma vez que sua sequência completa é carregada de significados culturais. Revela, também, as mudanças que esses significados sofrem no decorrer das suas trajetórias escolares.

d. Assim como as discussões, os materiais escritos produzidos pelos estudantes (de forma conjunta ou individual) são instrumentos valiosos para obter informações a respeito das mudanças que aconteceram (ou não) e como aconteceram.

e. Embora cada estudante da classe tenha características psicológicas e sociais muito peculiares, o processo de ensino precisa estar baseado no desenvolvimento de conhecimentos e habilidades comuns. Isso é possível, entre outras ações, pelas atividades em equipes e as apresentações, nas discussões em classe, e pela resolução de tarefas ou outras atividades em que os estudantes são incentivados a agir de forma deliberada e constante com seus pares.

f. As atividades e conhecimentos precisam transpor os limites da sala aula, ou seja, deve ser preocupação dos professores do PJA a criação de conexões significativas entre a realidade social e os conteúdos ensinados, e entre estes e a realidade social.

g. Da mesma forma que os estudantes aprendem e necessitam de assistência, os professores também necessitam dela, no que se refere à sua profissão. Portanto, também precisam de novos conhecimentos, assistência, apoio e feedbacks constantes. Algumas ações nesse sentido já são levadas em consideração, 
entretanto ainda há problemas de diferentes ordens que precisam vir à tona nos cursos de formação continuada, considerando o dia a dia dos professores.

Deixamos aos professores o desafio de aperfeiçoar suas práticas e buscar constantemente conhecer as estratégias, recursos e dinâmicas que estimulam o aprendizado de seus estudantes para que a relação em sala de aula seja sempre positiva.

Apontamos também, que nossa atenção foi despertada pelo fato de que, por se tratar de adolescentes conectados às novas tecnologias, eles não tenham dado ênfase aos recursos tecnológicos em sala de aula. Concluímos, por meio dos seus dizeres, que o que esperam de uma "aula legal" é muito menos complexo do que poderíamos imaginar para essa faixa etária.

\section{Referências}

ANASTASIOU, Léa das Graças Camargos; ALVES, Leonir Pessate. Processos de ensinagem na universidade: pressupostos para as estratégias de trabalho em aula. Joinville: Univille, 2004.

BAUER, Martin; GASKELL, George. Pesquisa qualitativa com texto, imagem e som: um manual prático. Rio de Janeiro: Vozes, 2002.

COLL, César. Aprendizagem escolar e construção do conhecimento. Porto Alegre: Artes Médicas, 1994.

COLL, César. Linguagem, atividade e discurso na sala de aula. In: COLL, César; MARCHESI, Álvaro; PALACIOS, Jesús. Desenvolvimento psicológico e educação: psicologia da educação escolar. 2. ed. Porto Alegre: Artmed, 2004. p. 261-279.

COLL, César; SOLÉ, Isabel. Ensinar e Aprender no contexto da sala de aula. In: COLL, César; MARCHESI, Álvaro; PALACIOS, Jesús. Desenvolvimento psicológico e educação: psicologia da educação escolar. 2. ed. Porto Alegre: Artmed, 2004. p. 242-260.

COUTINHO, Laura Maria Coutinho. Cinema e educação: um espaço aberto. Salto para o futuro. TV Escola: 2009. 38 p. vol. 4. Disponível em: <http://tvbrasil.org.br/ fotos/salto/series/185114Cinemaeedu.pdf>. Acesso em: 18 jan. 2012.

DELIZOICOV, Demétrio; ANGOTTI, José André; PERNAMBUCO, Marta Maria Castanho Almeida. Ensino de ciências: fundamentos e métodos. São Paulo: Cortez, 2002.

MARTíN, Elena; MAURI, Teresa. As instituições escolares como fonte de influência educacional. In: COLL, César; MARCHESI, Álvaro; PALACIOS, Jesús. Desenvolvimento psicológico e educação: psicologia da educação escolar. 2. ed. Porto Alegre: Artmed, 2004. p. 389-402.

PALACIOS, Jesús; OLIVA, Alfredo. A adolescência e seu significado evolutivo. In: 
COLL, César; MARCHESI, Álvaro; PALACIOS, Jesús. Desenvolvimento psicológico e educação: psicologia evolutiva. 2. ed. Porto Alegre: Artmed, 2004. p. 309-322.

POZO, Juan Ignacio. Aprendizes e mestres: a nova cultura da aprendizagem. Porto Alegre: Artmed, 2002.

POZO, Juan Ignacio; CRESPO, Miguel Ángel Gómez. A aprendizagem e o ensino de ciências: do conhecimento cotidiano ao conhecimento científico. 5. ed. Porto Alegre: Artmed, 2009.

SCHMITZ, Egídio. Fundamentos da didática. São Leopoldo, RS: Ed. Unisinos, 1993.

SENAC/SC/CSDS. Programa Jovem Aprendiz: orientação aos empresários.

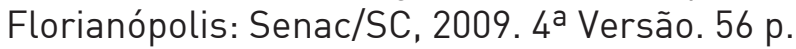

TOSI, Maria Raineldes. Didática geral: um olhar para o futuro. Campinas, SP: Alínea, 2001.

VASCONCELLOS, Celso dos Santos. Construção do conhecimento em sala de aula. São Paulo: Libertad, 2005.

VERGARA, Sylvia Constant. Métodos de pesquisa em administração. 2. ed. São Paulo: Atlas, 2006.

Recebido em outubro de 2012

Aprovado em janeiro de 2013

Ana Maria Venâncio Gonçalves Imhoff é mestre em educação pela Universidade Regional de Blumenau, na linha de pesquisa Aprendizagem e Desenvolvimento na Perspectiva Histórico-cultural. Email: anamaria.imhoffagmail.com

Camila Grimes é mestre em educação pela Universidade Regional de Blumenau, na linha de pesquisa Aprendizagem e Desenvolvimento na Perspectiva Históricocultural. Email:camilagrimesवibest.com.br

Edson Schroeder é doutor em Educação e professor pesquisador da Universidade Regional de Blumenau, atuando no grupo de pesquisa Processos de Ensinar e Aprender. Email:ciencia.edsondagmail.com 